\title{
STUDY ON AWARENESS AND EXPERIENCE OF SLEEP AND SLEEP-RELATED DISORDERS AMONG UNDERGRADUATE MEDICAL STUDENTS OF COASTAL ANDHRA PRADESH
}

Sai Shankar Pratap, Anand Acharya, Deepak, Sanjeev Rao

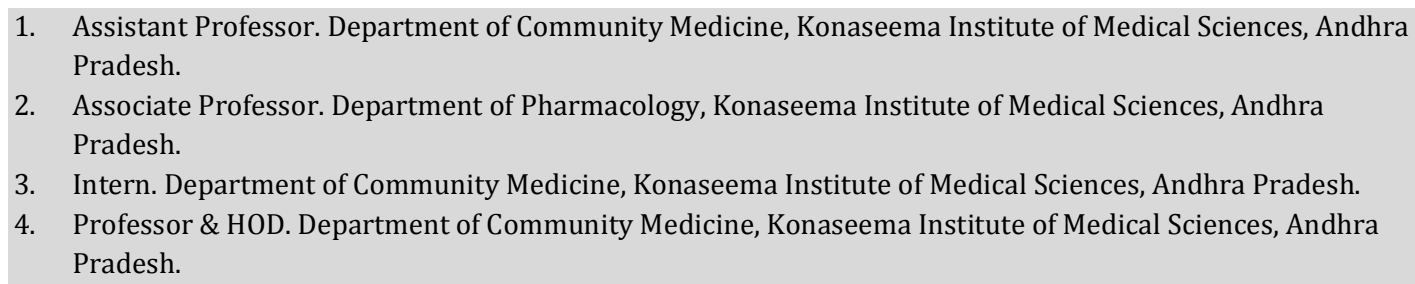

\section{CORRESPONDING AUTHOR:}

Dr. Sai Shankar Pratap,

Konaseema Institute of Medical Sciences,

Amalapuram, E.G. Dist. A.P.533201.

E-mail: prathapss@gmail.com

ABSTRACT: BACKGROUND: Sleep is an active, cyclic biological phenomenon necessary for survival. Sleep determines cognitive functioning, learning and attention, and also affects growth, behavior, and development. Sleep disorders are very common and are important unmet public health problems. Sleep medicine has not been emphasized in medical schools. Studies on awareness and sleep-related experiences in medical students are very limited and lacking. AIMS: To determine the awareness and experience of undergraduate medical students on sleep and sleep-related disorders. SETTINGS AND DESIGN: An institutional cross sectional study among undergraduate students of a medical college in coastal Andhra Pradesh. MATERIAL AND METHODS: After the study protocol was given clearance by the Institution Ethics Committee, consent was taken from the undergraduate medical students of Konaseema Institute of Medical Sciences and Research Foundation, Amalapuram, and a predesigned and pretested questionnaire was given which captured information related to basic demographic details followed by questions related to awareness and experience related to sleep and sleep disorders. STATISTICAL ANALYSIS: The data collected was entered into Microsoft Excel and analyzed using Epi Info 6 software. Chi Square test was done wherever applicable. RESULTS AND CONCLUSION: Total 432 out of 550 medical students (78.6 percent) participated in the study. There were 261 females and 171 males. Medical Students have suboptimal knowledge and even misconceptions regarding sleep - particularly sleep hygiene, sleep duration, sleep- related pharmacology and factors affecting sleep. Sleep-related problems are also very common in them. There is a need to emphasize sleep medicine in the curriculum of undergraduates and develop educational strategies to bridge the knowledge gap. The medical students need to know not only how to help others with sleep disorders, but also how to deal with themselves for their sleep related disorders

KEYWORDS: awareness, sleep-related experiences, undergraduate medical students

INTRODUCTION: Sleep is an active, cyclic biological phenomenon necessary for survival [1]. Sleep determines cognitive functioning, learning and attention, and also affects growth, 
behavior and development. We cannot function normally without adequate and good sleep. Sleep disorders, including disturbed sleep and suboptimal sleep, are very common but very small number of cases are identified or diagnosed by appropriate health care providers. Disturbed sleep is a common complaint and in the United States it has been estimated to affect up to 70 million Americans [2]. Sleep problems are seen in almost all age groups. The prevalence of particular kinds of sleep problems may vary with age, lifestyle, shift work, comorbid state. A study from France reported that 73 percent of the individuals surveyed complained of a nocturnal sleep problem and 9 percent had severe insomnia [3].A European multinational survey reported that prevalence of severe insomnia ranged from 4 percent to 22 percent [4]. Sleep disorders are associated with many diseases such as sleep-disordered breathing, encompasses various clinical disorders, including congenital central hypoventilation syndrome (CCHS), apnoea of infancy, sudden infant death syndrome (SIDS), obstructive sleep apnoea syndrome (OSAS), sleep-related worsening of chronic pulmonary disease, obesityrelated breathing abnormalities during sleep, and many others [5,6]. A study from Australia on economic cost of sleep disorders reported that the direct and indirect costs of sleep disorders were very high. The total financial costs (independent of the cost of suffering) were 4524 million USD which represented 0.8 percent of Australian GDP [7].

Sleep disorders and sleep deprivation are important unmet public health problems. There are a lot of missed opportunities for identifying sleep disorders in patients attending various clinics and the physicians must be sensitized to be on the lookout for these sleep disturbances so that appropriate treatment can be offered [8]. The problems associated with sleep disturbances can be identified and managed at the primary care level [9]. Use of prescription medication in patients with sleep difficulty was reported by 20 percent of men and 29 percent of women [10].

College students, especially medical students, experience a lot of academic, emotional and social stress and anxiety and hence are a high risk group for sleep disorders. Wolfson and Carskadon described that main correlates of poor academic performance are self-reported erratic sleep, wake schedule, short total sleep time, phase delay, and poor quality sleep [11]. Very few studies have been conducted on knowledge, behavior and practices of college students. In a study among medical students in Malaysia, it was found that sleep medicine knowledge was generally low. The authors had recommended educational strategies to improve knowledge regarding sleep-related problems and development of proper sleep practices [12]. Another study among medical students in Tamil Nadu reported that future doctors had insufficient knowledge with more misconceptions regarding sleep. The authors have recommended appropriate and immediate remedial action in the curriculum of medical undergraduates in the form of more time and emphasis placed in the subject of sleep. The study had identified compelling need to develop an educational strategy to overcome misconceptions and improve knowledge regarding sleep-related problems and proper sleep practices among students [13].

No related study could be found in the literature search regarding these problems in Andhra Pradesh. Hence we carried out a study to obtain information on sleep related knowledge and experiences of students of a medical college in East Godavari District of Andhra Pradesh.

METHODOLOGY: The protocol for carrying out the study was prepared and submitted for clearance of Institutional Ethics Committee of Konaseema Institute of Medical Sciences and Research Foundation, Amalapuram. After getting the clearance, a cross sectional study on awareness and experiences towards sleep and sleep related problems was carried out among 
the undergraduate medical students of this medical college in East Godavari district of coastal Andhra Pradesh. The study was planned to be carried out on all the students enrolled in MBBS in this college. An opportunity-type survey was planned and all the students who attended the college on the day of survey were told about the importance of this study and asked to participate. No attempt was made to collect data the students who were absent on the day of survey. A predesigned, pretested questionnaire was distributed among the students studying in different phases of MBBS in this college. The questionnaire was designed to collect information from the students and included provision to collect basic demographic details followed by questions related to awareness and experience related to sleep and sleep disorders. The questions touched certain basic concepts of sleep physiology, sleep related pharmacology, sleep requirements, sleep and toxicity of hypnotics, consequences of sleep deprivation, sleep-hygiene and the sleep related experiences of the study subjects. After taking their consent to participate in the study, the questions were explained and the students were asked to answer in the appropriate space provided in the questionnaire. The information provided by the students was entered into Microsoft Excel sheet, rechecked twice by independent persons for any errors, and analyzed using EPI INFO 6 software. Chi Square test was done to study any statistically significant differences in the study group.

RESULTS: There were 550 students studying in different phases of MBBS course in this institution. Out of these, 432 could be contacted and all of them had given consent for participation in the study. Thus, the participation rate was 78.6 percent. The study group comprised of 261 females and 171 males. The mean age of female subjects was 19.54 years with a Standard Deviation of 1.76 whereas the mean age of male subjects was 20.08 years with a Standard Deviation of 1.82. Nineteen female subjects had one or both of the parents working as a doctor, whereas twelve male subjects had one or both of the parents working as a doctor.

Table 1: Knowledge on sleep related issues among study subjects

\begin{tabular}{|l|l|l|l|l|}
\hline $\begin{array}{l}\text { Statement for assessment of } \\
\text { knowledge }\end{array}$ & $\begin{array}{l}\text { Total Students } \\
\text { with correct } \\
\text { knowledge } \mathrm{n}(\%) \\
{[\mathrm{N}=432]}\end{array}$ & $\begin{array}{l}\text { Males with } \\
\text { correct } \\
\text { knowledge n } \\
(\%)[\mathrm{N}=171]\end{array}$ & $\begin{array}{l}\text { Females with } \\
\text { correct } \\
\text { knowledge n (\%) } \\
{[\mathrm{N}=261]}\end{array}$ & $\begin{array}{l}\text { p- } \\
\text { value }\end{array}$ \\
\hline $\begin{array}{l}\text { Sleep disturbance is a } \\
\text { common problem }\end{array}$ & $226(52.3)$ & $143(83.6)$ & $83(31.8)$ & 0.00 \\
\hline $\begin{array}{l}\text { Sleep deprivation impairs } \\
\text { performance }\end{array}$ & $336(77.8)$ & $128(74.9)$ & $208(79.7)$ & 0.24 \\
\hline $\begin{array}{l}\text { Many psychiatric illnesses } \\
\text { present with insomnia }\end{array}$ & $238(55.1)$ & $101(59.1)$ & $137(52.9)$ & 0.18 \\
\hline $\begin{array}{l}\text { Children should not be } \\
\text { given sleeping pills }\end{array}$ & $399(92.4)$ & $155(90.6)$ & $244(93.5)$ & 0.28 \\
\hline $\begin{array}{l}\text { Drinking milk before bed } \\
\text { time promotes sleep }\end{array}$ & $264(61.1)$ & $97(56.7)$ & $167(64)$ & 0.13 \\
\hline $\begin{array}{l}\text { Small nap during daytime } \\
\text { may affect the quality and } \\
\text { quantity of sleep at night }\end{array}$ & $162(37.5)$ & $50(29.2)$ & $112(42.9)$ & 0.00 \\
\hline $\begin{array}{l}\text { Deprivation of sleep results } \\
\text { in psychiatric problem }\end{array}$ & $254(58.8)$ & $120(70.2)$ & $134(51.3)$ & 0.00 \\
\hline
\end{tabular}




\begin{tabular}{|l|l|l|l|l|}
\hline $\begin{array}{l}\text { Snoring is an indication of } \\
\text { deep sleep }\end{array}$ & $200(46.3)$ & $73(42.7)$ & $127(48.7)$ & 0.22 \\
\hline $\begin{array}{l}\text { Minimum of eight hours of } \\
\text { sleep is a must for every } \\
\text { human being }\end{array}$ & $72(16.7)$ & $28(16.4)$ & $44(16.9)$ & 0.90 \\
\hline $\begin{array}{l}\text { It is always better to } \\
\text { abruptly stop a sleeping pill } \\
\text { to avoid drug dependence }\end{array}$ & $138(31.9)$ & $52(30.4)$ & $86(33)$ & 0.58 \\
\hline $\begin{array}{l}\text { Reading/watching TV while } \\
\text { lying in bed is a good habit }\end{array}$ & $312(72.2)$ & $122(71.4)$ & $190(72.8)$ & 0.74 \\
\hline $\begin{array}{l}\text { One must take heavy meals } \\
\text { before going to bed to get } \\
\text { good sleep }\end{array}$ & $337(78)$ & $116(67.8)$ & $221(84.7)$ & 0.00 \\
\hline $\begin{array}{l}\text { Drinking alcohol promotes } \\
\text { good sleep }\end{array}$ & $183(42.4)$ & $64(37.4)$ & $119(45.6)$ & 0.93 \\
\hline $\begin{array}{l}\text { Regular exercise finished } 3 \\
\text { to 4 hours before sleep } \\
\text { adversely affects sleep }\end{array}$ & $177(41)$ & $72(42.1)$ & $105(40.2)$ & 0.70 \\
\hline
\end{tabular}

Knowledge related to sleep and sleep-related problems was sketchy in the study group. Only 52.3 percent of the study subjects know that sleep disturbance is a common problem, only 58.8 percent of study subjects knew that deprivation of sleep results in psychiatric problem, only 31.9 percent of study subjects knew that sleeping pills should not be stopped abruptly and only 42.4 percent of study subjects believed that drinking alcohol does not promote good sleep. Thus, there is deficiency of knowledge in the study subjects regarding sleep as a public health problem and also regarding sleep related physiology, pathology and pharmacology. There was not much difference between the knowledge of male and female study subjects on most of the issues related to sleep. However, a significantly higher proportion of males $(p=0.00)$ knew that sleep disturbance is a common problem than females. Similarly, a significantly higher proportion of male subjects $(\mathrm{p}=0.00)$ also knew that deprivation of sleep leads to psychiatric problems. A significantly higher proportion of female subjects $(\mathrm{p}=0.00)$ knew that small nap during daytime does not affect the quality and quantity of sleep at night. Similarly, a significantly higher proportion of female subjects $(p=0.00)$ also had the knowledge that intake of heavy meals before going to bed does not help in getting a good sleep.

Information regarding sleep related experiences of the study subjects in the last one week before the study was also collected. This is depicted in the Table 2 below:

Table 2: Sleep related experiences of the study subjects in the last one week before the study

\begin{tabular}{|l|l|l|l|l|}
\hline Sleep-related experience & $\begin{array}{l}\text { Total Students } \mathrm{n} \\
\text { (\%) who had this } \\
\text { experience } \\
{[\mathrm{N}=432]}\end{array}$ & $\begin{array}{l}\text { Males } \mathrm{n}(\%) \text { who } \\
\text { had this } \\
\text { experience } \\
{[\mathrm{N}=171]}\end{array}$ & $\begin{array}{l}\text { Females } \mathrm{n}(\%) \\
\text { who had this } \\
\text { experience } \\
{[\mathrm{N}=261]}\end{array}$ & $\begin{array}{l}\mathrm{p}- \\
\text { value }\end{array}$ \\
\hline $\begin{array}{l}\text { Trouble falling asleep (did } \\
\text { not get sleep at normal } \\
\text { time and had to stay awake }\end{array}$ & $173(40.1)$ & $56(32.8)$ & $117(44.8)$ & 0.01 \\
\hline
\end{tabular}




\section{ORIGINAL ARTICLE}

\begin{tabular}{|l|l|l|l|l|}
\hline for a longer time) & & & & \\
\hline $\begin{array}{l}\text { Had to wake up several } \\
\text { times during night }\end{array}$ & $93(21.5)$ & $29(17)$ & $64(24.5)$ & 0.06 \\
\hline $\begin{array}{l}\text { Had trouble staying asleep } \\
\text { (woke up earlier than } \\
\text { usual) }\end{array}$ & $102(23.6)$ & $42(24.6)$ & $60(23)$ & 0.71 \\
\hline $\begin{array}{l}\text { Woke up feeling tired and } \\
\text { worn out }\end{array}$ & $154(35.7)$ & $59(34.5)$ & $95(36.4)$ & 0.69 \\
\hline $\begin{array}{l}\text { Felt sleepy during daytime } \\
\text { hours }\end{array}$ & $287(66.4)$ & $111(64.9)$ & $176(67.4)$ & 0.59 \\
\hline
\end{tabular}

Sleep-related problems are found to be common in the study group and 40.1 percent of the subjects reported that they had trouble falling asleep (did not get sleep at normal time and had to stay awake for a longer time) in the last one week before the study. Also, 66.4 percent of study subjects felt sleep during the daytime in that week. The sleep related experiences of study subjects in the last one week before the study were almost similar in both males and females. However, a significantly higher proportion of female study subjects $(\mathrm{p}=0.01)$ had trouble falling asleep in that week.

DISCUSSION: This study suggests that knowledge of undergraduate medical students on some of the important issues related to sleep is deficient. Similar finding was reported in a study done in Tamil Nadu [13]. Overall, a fairly wide knowledge gap on sleep related issues can be identified among the study subjects from the results. Low levels of knowledge amongst the undergraduate medical students can have serious implications during their future clinical practice. They will not be able to optimally manage the patients with sleep related disorders unless the knowledge gap is bridged effectively.

A study done in Tamil Nadu reported that there was no significant sex difference regarding sleep practices among undergraduate medical students. The same study has also reported that only less than 20 percent felt well rested [13]. However, the present study findings show that a significantly higher proportion of female study subjects had trouble falling asleep and that about two-thirds of the study subjects felt well rested.

Study from US has reported that sleep related education in medical curriculum is inadequate [14]. Studies have recommended continuing medical education as a medium for additional education on sleep related issues for medical students and practitioners [15].

CONCLUSIONS: This study has revealed that the knowledge of the undergraduate medical students on sleep related issues is inadequate and this can have implications on the way the practice medicine once they pass out of the medical college. There is a definite need to emphasize sleep related issues in the medical curriculum. This study has also revealed that sleep related problems are common in undergraduate medical students. These doctors-inmaking need to know not only how to help others with sleep disorders, but also how to deal with themselves for their sleep related disorders.

ACKNOWLEDGEMENTS: The authors express their heartfelt thanks to Dr. Vishwanath, Dr.B.Praveen and Dr.Ch.Kiransri for their assistance in data collection. The authors also express a special thanks to all the students who participated in study. 


\section{REFERENCES:}

1. Kryger MH, Roth T, Dement WC. Principles and practice of sleep medicine. 2nd ed. Philadelphia: WB Saunders, 2000.

2. Rosen RC, Zozula R, Jahn EG, Carson JL. Low rates of recognition of sleep disorders in primary care: comparison of a community-based versus clinical academic setting. Sleep Med 2001; 2:47-55.

3. Leger D, Guilleminault C, Dreyfus JP, Delahaye C, Paillard M. Prevalence of insomnia in a survey of 12,778 adults in France. J Sleep Res. 2000;9: 35-42.

4. Chevalier H, Los F, Boichut D, et al. Evaluation of severe insomnia in the general population: results of a European multinational survey. J Psychopharmacol. 1999;13 (suppl1):S21-S24.

5. Gaultier C, Guilleminault C. Genetics, control of breathing, and sleep-disordered breathing: a review. Sleep Med 2001; 2:281-95.

6. Santiago JR, Nolledo MS, Kinzler W, Santiago TV. Sleep and sleep disorders in pregnancy. Ann Intern Med 2001; 134:396-408.

7. Hillman DR; Murphy AS; Antic R et al. The economic cost of sleep disorders. SLEEP 2006;29 (3):299-305.

8. Blais FC, Morin CM, Boisclair A, Grenier V, Guay B. Insomnia. Prevalence and treatment of patients in general practice. Can Fam Physician. 2001;47:759-767

9. Blanquer JJ, Ortola P, Rodriguez JJ, Marin N, Mulet MJ. An epidemiological analysis of insomnia at a primary care center. Aten Primaria. 1994;14:609-614

10. Olson LG. A community survey of insomnia in Newcastle. Aust N Z J Public Health. 1996;20:655-657

11. Wolfson AR, Carskadon MA. Understanding adolescents sleep patterns and school performance: a critical appraisal. Sleep Med Rev 2003; 7: 491-506.

12. Redhwan Ahmed Al-Naggar, Ramli Musa, Karim Al-Jashamy, Zaleha Mohd Isa. Knowledge, attitude and practice towards sleep among medical students of International Islamic University Malaysia. ASEAN Journal of Psychiatry, Vol 11 (1): JanJune 2010. XX XX

13. Sivagnanam G, Thirumalaikolundusubramanian P, Sugirda P, Rajeswari J, Namasivayam K, Gitanjali B. Study of the knowledge, beliefs and practice of sleep among medical undergraduates of Tamil Nadu, India. Med Gen Med 2004; 6(4):5.

14. Rosen R, Mahowald M, Chesson A, et al. The Taskforce 2000 survey on medical education in sleep and sleep disorders. Sleep. 1998; 21: 235-238.

15. Owens JA. The practice of pediatric sleep medicine: results of a community survey. Pediatrics. 2001;108:E51 